\title{
READERS
Insight
}

Journal of Management Info (JMI)

ISSN:2313-3376

www.readersinsight.net/jmi

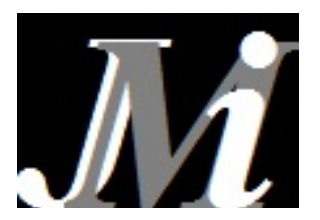

\section{Influence of celebrity endorsement on consumer purchase intention for existing products: A comparative study}

\author{
Syed Rameez ul Hassan ${ }^{1}$ Raja Ahmed Jamil ${ }^{2 *}$ \\ ${ }^{1,2}$ Department of Management Sciences, University of Haripur, Pakistan
}

* Corresponding author: raja.ahmed@uoh.edu.pk

\begin{abstract}
Advertisement by Involvement of celebrities has become an essence in modern competitive marketing environment for high recognition and creation of strong product perception. Celebrity endorsement is the main focus of the study where Pakistani and Indian celebrities with their attributes are used for their endorsement effect on purchase intention. A sample of 300 was taken to assess the contrast between Indian and Pakistani celebrity endorsement effects on purchase intention in Pakistan. Similar and competitive brands are chosen which are endorsed by Pakistani and Indian Celebrities separately. Results of the study showed that endorsement through local and Indian celebrities has similar and not much significant influence on purchase intention in Pakistan, with no major difference by country of origin of celebrity. In the study consumer celebrity relationship is assessed and it confirms that attributes of celebrity (Local or Indian) are not much important for intent to purchase for existing products but quality, brand image and brand loyalty are the key factors for intention to purchase. Implication for research and practice are discussed.
\end{abstract}

\section{ARTICLE INFORMATION}

Received: 25 August 2014

Revised: 25 November 2014

Accepted: 25 December 2014

DOI:

http://dx.doi.org//10.31580/jmi.v4i1.18

\section{Introduction}

Advertisement is "the art of persuasion" that is mainly concerned to create awareness about what is being offered with ultimate objective to persuade towards buying. Since the last ten years, it has been seen that marketing environment changed significantly and witnessed the involvement of celebrities in advertisement. Celebrity endorsement has been defined as: "Any individual who enjoys public recognition and who uses this recognition on behalf of a consumer good by appearing with it in an advertisement" (McCracken, 1989). It is really worth mentioning that why organizations spend a lot on brands by involvement of celebrity to endorse. Celebrities are well recognized personalities having a strong attractive and impressive power to pursue the audience either by their likeliness, attractiveness, trust or by their congruency with brand which leads in creation of strong brand image and value in viewers' minds. Available literature on endorser effect gives clear information that how value is transferred (McCracken, 1989) by celebrity for promotion brand and creating awareness for the brand by celebrity characteristics, credibility, attractiveness (Pornpitakpan, 2004) and image congruence (Choi et al., 2005).

Consumers of the product are much effect by celebrity when they believe that endorser has actual attachment with product rather than materialistic gain. Numerous studies have similar views that the involvement of celebrities in advertisement shows successful results on credibility, communication evoke, recall and likeability of the advertisements and finally on purchase intentions (Menon et al., 2001; Lafferty and Golsmith, 1999).

Therefore it becomes an essence to introduce or to support the product by well-known and credible personality in a competitive marketing world. In order to increase the market share of product most of the popular brands are currently endorsed by celebrities in Pakistan media who did successful endorsement particularly Lux by Shahrukh Khan and Katrina, Head and Shoulders by Shahid Khan Afiridi, Lux by Reema Khan, Supreme Tea by Akshay Kumar and Sunakshi, Saif Ali khan and Kareena Kapoor for Head \& Sholders, Katreena for Veet Cream, Pentiene, Ali Zafar for Lipton Tea etc., with all having single aim in mind to acquire faster brand recall, product preferences and eventually product purchase. Advertisements mentioned above give a vivid picture about the emergence of Indian celebrities along with Pakistan Celebrities for similar as well as competitive brands.

Mass media communication provides source to organizations for focusing on cultural deviance effects in their ads for making them more appealing and attention capturing. Celebrities are cultural symbols who reflect the values and ideas of a particular culture. And, therefore, the ways such "personas appear in advertising and their impacts may vary from culture to culture" (Choi, Lee \& Kim, 2005). In the same manner, it is a question that whether Indian celebrities are effective source endorsers in Pakistan while comparing them with local celebrities. It is a fact that Indian celebrities are much familiar in Pakistan like local celebrities through mass media and similarities of cultures between these two countries. In this study we make a comparison that whether Indian or local celebrities are more effective, attention capturing and appealing towards purchase intention in Pakistan.

This analysis is much useful for assessing consumer celebrity relationship to show how strong the consumer relationships are between the homeland celebrity endorsers in Pakistan and Indian celebrity endorsers in Pakistan and their influences on purchase intentions for existing products.

\section{Literature review}




\section{Celebrity endorsement}

"Celebrity endorser is an individual who is known by the public for his or her achievements in areas other than that of the product class endorsed" (Friedman \& Friedman, 1979).

Multinational organizations' attachment of celebrities with their brands is additional effort exerted in ads, in order to gain more popularity of the product and its easy recognition for the purpose of purchase motivation. Intense attachment with celebrities attracts the people and motivates them to follow the celebrity (McCuthceon, Lange and Houran, 2002). On communication side, in China a strong positive effect is created by celebrity endorsement practices (Gan, 2006). Celebrities are inviters who invite the people to buy the product or service with enormous power in Ads than any other due to their credibility and distinctive position that leads towards intention to buy. In current marketing environment attention capturing towards Ads is also done by the endorsers which produce positive results to advertisement and greater purchase intentions (Brajesh and Gouranga, 2011).

Celebrities are considered to bring attention towards advertisement due to their likeability and attractiveness (Erdogan, 2001). Celebrity in advertisement is chosen not only on the basis of popularity but also accessing the several dimension of celebrity for the best match with product they are endorsing, how suitable Junaid Jamshed will be in Ad of toilet cleansers, or a male for endorsing women fairness creams? In the same way endorser's physical attractiveness is also a big count for great social acceptance. So with brand attributes celebrity attributes are of the same importance for success of the product. Erdogan (1999) focused that persuasive and convincing technique of celebrity is based on attributes attached with celebrity which make endorsement more effective.

On other hand contrary analysis has also been done by the researchers like that of over endorsement, or if celebrity goes bad and nonprofessional then there will be negative effect of celebrity endorsement on product. Increase in number of brands endorsed by celebrity decrease the celebrity worth and influential power (Tripp et al., 1994). Celebrity's involvement in negative event makes them less encouraging or appealing to the product or service they endorse (White et al., 2009).

On the basis of previous analysis, most of studies it is supported that celebrity endorsers have positive influence on purchase intentions. Several studies support that similar ethnic group celebrities are effective on purchase intention. As Indian stars are becoming more famous due to mass media and Bollywood quality films in Pakistan. As the popularity of Indian celebrities increases, it leads a sort of attachment with Indian celebrities like Shahrukh Khan, Salaman Khan, Katrina Kaif etc. On the basis of celebrity cultural similarity and intense attachments with celebrity and number of successful brand endorsement done by Indian celebrities in Pakistan media. The following section discusses various dimensions of celebrity, their country origin and effect on consumer purchase intention.

\section{Dimensions of celebrity endorsement}

\section{Physical attractiveness}

Accordung to Patzer (1985), "Physical attractiveness is an informational cue which involves effects that are subtle, pervasive, and inescapable; produces a definite pattern of verifiable differences; and transcends culture in its effects".

According to Ohanian (1991), "Beauty is a greater recommendation than any letter of introduction".

Celebrity endorser's Physical attractiveness got great social appraisal and acceptability. It is a source to capture attention of audience both in print and electronic media; Physical attractiveness has positive effect on consumer's behavior toward the product and service while making comparison of product with the person who is unattractive (Ohanian, 1991). A study finding about Razor reveals that attractiveness of celebrity produces significant results as people are themselves conscious about their own attractive looks (Kahle and Homer, 1985). Similarly, those entire products which are linked with person's physical attractiveness or facial looks e.g. facial creams, beauty soaps, dresses, hair colors and shampoos etc. are much influenced by physical attractiveness of celebrity. Physically attractive celebrities are also useful for the principle of match up theory at the time of selecting celebrity where attractiveness is more influential (Kamins, 1990). Physical attractiveness is a tool to change attitude (Menon et al., 2001).

So physical attraction is powerful source to influence the people by their look and style and create significant influence on purchase intention. As Indian celebrities like Bollywood stars exposed (Veet by Katrina) themselves by using miniskirts or attention capturing dresses in Ads which creates more attention towards opposite gender and such appearance makes them more attractive and easier to recall. On the other hand, Pakistan celebrities are of their own importance in this regard within social restraints and religious limits. Thus we drive our hypothesis as:

H1: Physical attractiveness of Indian celebrities has greater influence on purchase intention than Pakistani celebrities.

\section{Credibility / trustworthiness}

Trust worthiness refers to the "honesty, integrity and believability of an endorser" (Erdogan, 2001). Consumer has generally a consideration that celebrities are trustworthy source of communicating information (Goldsmith et al., 2000). It is general principle a person you trust upon is a source to easily convince you to believe in unseen thing, that person is more believable than any other in community. In addition if such person is also an expert in the field for which he or she is advocating is more persuasive. It is supported to "the extent to which the recipient sees the source as having relevant knowledge, skills, or experience and the source to give unbiased, objective information" (Belch \& Belch, 1994). In similar measures a celebrity in message of advertisement become really effective if it is judged that who is the speaker, who is saying; how much is that person believable? Celebrity in an advertisement with expertise is more trustworthy or believable (Hung et al., 2011). Erdogan (1999) argued that celebrity endorser's credibility is not a single source but a valuable source having cognitive and positive effects on intent to purchase. It is trustworthiness upon celebrity that also reduces the effects of rumors or bad. An interesting factor for increasing trust on celebrity is confirmed by Desphande and Stayman (1994) ethnic status because level of confidence on people similar to them is significantly high than that of endorser from any other ethnic group. It means that the celebrity belongs to similar region, having same lifestyle with targeted group is considered to be more credible.

In case of Indian and Pakistan celebrity endorsement it is interesting that large number of similarities exist even in some cases same religion (Shahrukh Khan, Salman Khan and Shahid Afridi) but difference of beliefs are also noticed (Kareena and Mahnoor Balooch). Apart from this all other attributes of celebrities whether from Indian or Pakistan are almost same, but levels of attachment with local celebrities is somehow considered more than that of Indians celebrities due to similarities in beliefs and origin of country. Hence we propose our hypothesis as:

H2: Local celebrities are more trustworthy for motivating to purchase than that of Indian celebrities.

\section{Celebrity expertise}

Term expertise is defined as "the extent to which a communicator is perceived to be a source of valid assertions" (Hovland et al., 1953). In order to persuade recipients of information endorser's expertise has encouraging effect on receivers (Ohanian, 1990). Belch \& Belch (1994) said that information receivers have strong belief upon the person who is practical having related knowledge, expertise in advocating area. Endorser with high knowledge and skills has strong power of recommendation as compare to the endorsers with low expertise (Ohanian, 1990).Celebrity expertise is one of the reasons in order to find out its influence on recipients of information (Amos, Holmes \& Strutton, 2008). If the celebrity advocating the product has strong knowledge and experience, then he/she will ultimately have differential power to pursue due to strong believability. Hence we hypothesize: 
H3: Pakistani Celebrities are considered to have more expertise than that of Indian celebrities.

\section{Celebrity congruence}

Celebrity matchup principle with product is as important as all other attributes pertains to celebrity for high social acceptability and strengthening the credibility of celebrity (Kamins, 1990; Kotler, 1997). Product and celebrity association is most important factor for generating positive feedback because people take it as evidence that product is in reality used or consumed by celebrity. If logically audience does not accept the celebrity as perfect match with what they are endorsing is nothing but only unnecessary expenditure. "Moderately incongruent endorsers did not perform better than extremely congruent ones" (Jagre et al., 2001). Fortini-Campbell (1992) found that people consume those brands which have some association with personalities e.g. relates the brand with own personality, colleagues, fellows, family members or Celebrity. Match up of source endorser gains is supported by the study of Misra and Beatty (1990) that product is easily "recall and affect" is improved by the similarity between source endorser and brand. Brand celebrity matchup study supports congruence principle and its effectiveness (Roy, 2006). Another study for significant effect of celebrity congruence is being interconnected between celebrity and the brand which creates strong perception for audience about expertise (Ohanain, 1991). People desire to identify the product with source and so congruity of source with product is much important (Kamins and Gupta, 1994).

Consumers are more attracted to the product if they believe that what is endorsed by celebrity is actually being used by the celebrity and their effects are prominent by their personality. In advertisement in Pakistani media, emotional match up (Family Care Products like Dettol etc.), Attractiveness Match up, Credibility match up all are supported by celebrities used in Ads whether Indians or Pakistani's. Therefore it is hypothesized:

H4: Local celebrities are considered to be more congruent with product endorsing than that of Indian Celebrities.

\section{Purchase intention}

Refers to plan to buy something in future for use but prior to this a cognitive process works behind where several factors consumer perception about product or source person really matters. In purchase intention process main focus of the study is the attitude towards the source person, Celebrity endorser. The attributes of celebrity develop the attitude towards buying. Amos, Holmes and Struton (2008) consumer's positive attitudes about source celebrity who endorse the brand enhance the intention towards the buy. Ohanian (1991) Purchase intention is the only result of single celebrity attribute that is his expertise rather than any other. Message of advertisement is easily recalled and likeability of ad increases due to involvement of celebrity which results in purchase intention (Pringle and Binet, 2005). Indirect association with intention to purchase and source endorser is also found positive toward product by using advertisement as medium (Goldsmith et al., 2000) .If product attributes are not considered in detail by consumer than they opt with celebrity endorsement to purchase (Lafferty and Goldsmith, 1999). Significant results about purchase intention by involvement of celebrity are also found by (Yoon et al., 1998) according to him attractiveness has more influencing power on purchase intention.

On the counter part researches also point out the negative effect of celebrity endorsement. Celebrity effectiveness declines by over endorsement and has negative relation with purchase intention (Tripp et al., 1994). Association of negative event with celebrity endorser also has adverse effects on buying behavior (White et al., 2009).

From the available literature it is found true that celebrity endorsement has significant influence on purchase intention of consumer. Attractiveness of celebrity, their congruency, and believability all these factors have positive influence towards buying behavior. In contrast to Indian Pakistani celebrities, if one celebrity is considered to be physical attractive than the other is considered to be more believable and so on. Different celebrities share different attributes at different and same time as well. Therefore both country celebrities are used in current ads. Increasing emergence of Indian celebrities by reputable brands in Pakistan media gives an idea that organization got benefits by doing so. At the same time Pakistan celebrities are also seen in the ads of similar brands. On the basis of this, it is considered that celebrities of both countries are of their own importance in influencing purchase intention.

\section{Methodology}

\section{Population and sample}

For accomplishing the purpose of study data is collected from university students and household through self-administrative questionnaires. Questionnaires were distributed to people age between 17 to 40years and their qualification ranges between F.sc to Masters with a vision about true findings of the studies on the contrary to this other people with lower qualification are properly guide in order to have their true representation at the time of responding to questionnaire .

Main aim for selecting the said population is that young people having keen interest and awareness about what is being offered by advertisement and by whom it is endorsed so they can easily recall for making linkages and respond correctly for presented questions. Another significance of said population is that they are targeted potential customers for the product offered by the companies.

Sample size for the study is three hundred for which three hundred (300) questionnaires were distributed from which two hundred and ninety eight (298) questionnaires are received back from which (295) are useable and got high response rate of ninety nine percent $(99 \%)$. Reason for high response rate is that we got questionnaires filled on the spot by respondent after complete briefing. Another reason for high rate of response is interest of students as they know the worth of research.

\section{Design}

Distributed questionnaires contain total Six (6) celebrities printed each celebrity on set of questionnaires in following manner, three celebrities from Pakistan and three celebrities from India are taken who are endorsing products in Pakistan electronic media especially at cable network. By dividing three hundred questionnaires by six, each celebrity has got equal number of fifty (50) questionnaires. Current Ads in Pakistan media are chosen for easily recall by respondents in which similar brands Head and shoulders (endorsed by Saif Ali Khan, Indian celebrity and also by Shahid Khan Afridi, Pakistan celebrity) and competitive brands are Lipton and Supreme (endorsed by Ali Zafar, Pakistan celebrity and by Akshay Kumar, Indian celebrity consecutively).

Male and female celebrities from both countries are taken into consideration in order to minimize the effect of opposite gender attraction of respondents. Where the advertisement contains both Male and Female celebrities, it is on discretion of respondent to choose any one from them to answer the asked questions (Saif Ali Khan and Kareena are in Ad of Head and Shoulders so respondents can choose any one of them by marking check symbol). By taking different celebrities it also tries to minimize the effect of personal liking and disliking of a particular celebrity, so we will find true results of study.

Questionnaires which are distributed among university students are explained during their classes by permission of lecturer and make couples of students. Then distribute two questionnaires to each couple containing one Pakistani and other containing Indian celebrities afterwards they are told to fill questionnaire by making comparative analysis between given celebrities and from couple every individual fill single questionnaire for either Indian celebrity or Pakistan celebrity.

For households two questionnaires are given to each family and explained the purpose of study so they are told to fill questionnaires by making comparison between Pakistan and Indian celebrities only two family members are allowed to take part in this practice. It is worth mentioning that throughout the process of questionnaire scoring 
data collecting representatives are present with respondents for their assistance both in university and households

It is also clearly explained to respondents that by this study we are checking the effectiveness of celebrity endorsement in Pakistan media (by their country origin of celebrity).

\section{Data analysis}

For analyzing the data SPSS is used where several tests are run to find out Missing Values and outliner analysis, Reliability Analysis, mean and standard deviation calculation, One-way ANOVAs for control variables, Correlation Analysis for finding relationship between variable of interest and Linear Regression Analysis for accessing effect of independent variables on dependent variable.

\section{Scale or measures used}

Instruments used for data collection which is developed by Ohanian (1990) on five point Likert scale for his research work about Celebrity Endorsement in which three dimensions about celebrity are accessed by 5items which are Celebrity Attractiveness, Trustworthiness, Expertise, and purchase Intention by 3 items.

\section{Reliability test}

Celebrity Attractiveness 5items questions ranges between Strongly Agree to Strongly Disagree on five point Likert scale for accessing the physical attractiveness of celebrity and its effects on purchase intent for both Indian and Pakistan celebrities. Asked question includes (Attractive/unattractive) and found alpha reliability of Pakistan and Indian Celebrities consecutively (0.791 and 0.810). In the same way question regarding Trustworthiness of celebrity (Dependable/Not dependable, Trustworthy/Not Trust worthy etc.) and its alpha reliability found for Pakistan and Indian Celebrities respectively (0.871and .860) and for Celebrity Expertise (Expert/Not expert, Experienced/Un experienced etc.) where alpha reliability of Pakistan and Indian Celebrities respectively (0.789 and .801) were founded. For Celebrity Congruence with brand questions used were (Congruency of celebrity with brand, believability about celebrity endorsing that brand, whether celebrity is user of that brand etc.) on rating between strongly agree to strongly disagree and found alpha reliability of Pakistan and Indian Celebrities respectively (.761 and .710) with 4items. As for response to celebrity endorsement effect on purchase intention 3items were used on five point Likert scale ranges between Very Likely to Very Unlikely and found Alpha reliability of (.917 and .944) for Pakistan and Indian Celebrities respectively. We used all the standardized questionnaire used in previous studies were adopted from (Ohanian, 1990; Kamins and Gupta, 1994; Khale and Homer, 1985).

\section{Correlation matrix}

Correlation Analysis Indicates that attractiveness of Indian celebrities has weak positive but significant relationship $\left(.165^{*}, \mathrm{p}<\right.$ $.05)$ on purchase intention than that of Pakistani celebrities.

Table: 1 Mean, S.D, Correlation and Reliability Pakistan ( $\mathrm{N}=295)$

\begin{tabular}{|c|c|c|c|c|c|c|}
\hline & Mean & S.D & 1 & 2 & 3 & 4 \\
\hline CATT & 2.21 & 0.74 & & & & \\
\hline CCRE & 2.49 & 0.87 & $.326^{* *}$ & & & \\
\hline CEXP & 2.22 & 0.7 & $.437^{\star *}$ & $.478^{* *}$ & & \\
\hline CCOG & 2.42 & 0.84 & $.364^{* *}$ & $.564^{* *}$ & $.506^{\star *}$ & \\
\hline PINT & 2.85 & 1.21 & 0.06 & 0.1 & $.225^{* *}$ & $.168^{*}$ \\
\hline \multicolumn{7}{|c|}{ Indian ( $\mathrm{N}=295)$} \\
\hline & Mean & S.D & 1 & 2 & 3 & 4 \\
\hline CATT & 2.03 & 0.79 & & & & \\
\hline CCRE & 2.83 & 0.86 & $.410^{* *}$ & & & \\
\hline CEXP & 2.28 & 0.78 & $.285^{\star *}$ & $.607^{\star *}$ & & \\
\hline CCOG & 2.57 & 0.81 & $.380^{\star *}$ & $.479^{* *}$ & $.378^{\star \star}$ & \\
\hline PINT & 2.99 & 1.21 & $.165^{*}$ & 0.053 & $.173^{*}$ & $.213^{* *}$ \\
\hline
\end{tabular}

In the same way for celebrity expertise for both countries celebrities have weak but positive correlation with purchase intention: Indians $\left(.17^{*}, \mathrm{p}<.05\right)$ and for Pakistanis' $\left(.225^{* *}, \mathrm{p}<.01\right)$ Celebrity Congruity has also weak but positive significant correlation for Pakistanis and Indians celebrities given consecutively $\left(.168^{*}, \mathrm{p}<.05\right)$ and $\left(.213^{* *}\right.$, $\mathrm{p}<.01)$.

\section{Regression analysis}

\section{Celebrity attractiveness}

Linear regression was performed to test all the independent variables and their effect on dependent variable result shows that as far as attractiveness is concerned Indian celebrities has positive but insignificant effect purchase intent $(\beta=.12, \mathrm{p}$. ns) while for Pakistani celebrities $(\beta=-.06, p$. ns) therefore our hypothesis 1 become un true that Indian celebrities attractiveness has significant influence on intent to purchase in Pakistan, thus hypothesis is rejected.

Table 2: Results of Regression Analyses (Indian Study)

\begin{tabular}{|c|c|c|c|}
\hline \multirow[b]{2}{*}{ Predictors } & \multicolumn{3}{|c|}{ Dependent Variable } \\
\hline & B & $\mathbf{R}^{2}$ & $\Delta \mathbf{R}^{2}$ \\
\hline Step 1: & & & \\
\hline CATT & .12 & & \\
\hline CCRE & -.21 & & \\
\hline CEXP & .19 & & \\
\hline CCOG & .19 & .08 & .08 \\
\hline
\end{tabular}

\section{Celebrity credibility}

As it was hypothesized that Pakistani celebrities are more credible for making beliefs and motivate to purchase but results of regression for Pakistan celebrities shows negative and insignificant results $(\beta=-$ .004, p. ns) and for Indian Celebrities $(\beta=-.20$, p. ns) therefore credibility of Pakistan and Indian celebrities have inverse effect on purchase intention and hypothesis 2 is rejected.

Table 3: Results of Regression Analyses (Pakistan Study)

\begin{tabular}{llcl}
\hline \multicolumn{4}{l}{ Dependent Variable } \\
\hline Predictors & $\mathbf{B}$ & $\mathbf{R}^{\mathbf{2}}$ & $\mathbf{\Delta R}^{\mathbf{2}}$ \\
\hline Step 1: & & & \\
CATT & -.06 & & \\
CCRE & -.04 & & \\
CEXP & .22 & & \\
CCOG & .10 & .06 & .06 \\
\hline
\end{tabular}

\section{Celebrity expertise}

Celebrity expertise regression results show positive and significant $(\beta=.22, p<.01)$ impact on purchase intention in comparison with Indian Celebrities where $(\mathrm{B}=.19 \mathrm{p}$. ns).Therefore Pakistani celebrities are considered to be more and knowledge than Indian celebrities thus positive influence on purchase intention, so hypothesis 3 is accepted.

\section{Celebrity Congruence}

In order to analyze matchup principle of celebrity with brand endorsing, Indian celebrities have positive and significant effect on intent to purchase $(\beta=.19, \mathrm{P}<.05)$ while for Pakistan celebrities $\quad(\beta$ $=.10, \mathrm{p}$. ns) positive and insignificant relation exists, therefore stipulated hypothesis 4 is rejected on the base Indian celebrities are more congruent with product endorsed by them in Pakistan media in contrast with Pakistan celebrities.

\section{Discussion}

Celebrities are considered as being the persuasive element in marketing in this study. As for celebrity attractiveness negative relation is found between attractiveness of celebrity and their effect on purchase intention in Pakistan. The basic reason behind this relationship is that consumers are quality consciousness and hold practical experience for making any positive or negative assertion about product rather than physical outlook of celebrities. Another reason for mismatch result is that famous products have already 
strong images in consumer minds such that they are least concerned about attractiveness of celebrity and most of well-known products are only endorsed by famous personalities. Therefore physical appearance is way to capture attention towards Ads, not influencing the purchase. Due to strong affiliation of people with brands they are not much inspired by attractiveness but care more about taste, quality and affiliation with product.

Credibility side of celebrity's dimension again in this study reveals interesting but varied results that celebrities in current Ads are not enough credible to be believed upon for purchase intention. Reason behind this is that a few celebrities have hold on endorsement in Pakistani media and they are seen repeatedly on media even endorsing too many competitive brands with a frame of couple of months' time. This is also supported by literature; celebrity loses his/her worth by increasing number of brands (Tripp et al. 1994). Show biz celebrities (Models, Actors, Hereon) all are professional so financial gains are important to them rather than interest of consumer, so people in Pakistan did not rely upon them while making purchase decision. Now here again it is worth mentioning to repeat that sales of those products are due to prior taste, experience or loyalty but not due to credibility of celebrities who are appearing in current ads.

As for expertise is concerned Pakistani celebrities are considered to be more expert, motivating the consumers to buy because they know the preferences of consumers due to belongingness to the same country. Due to this know how they act in a way which gives more realistic emotional effect in ads. Addition to this Pakistani celebrities usually rely on emotions in Ads which is also an expert technique as that Pakistani people make most of decision on emotional basis for family and friends.

In case of Congruence again results are contrary to our hypothesis where results shows Indian celebrities are more congruent with product endorsed. Indians celebrities who are involved in Ads in Pakistan are top of the list celebrities, they are elegant so have match with most of the products. It is due reason that Pakistan sports players are usually endorsing several brands which are not very congruent with their personalities and few models which are replaced soon by other models for same products, while Indian celebrities are mostly film stars their physical match with product is outstanding in the Ads of Shampoos, Soaps, Facial creams other related products.

\section{Managerial recommendations}

From the study it is analyzed that brand managers should focus on quality more rather than increasing their cost by hiring international celebrities.

As it seems that purchase intention is result of brand image so product with strong brand image do not need to rely upon famous personalities.

In country like Pakistan direct marketing approach is much effective where the word of mouth and front line employees who are in direct contact with consumers are more effective for stimulating purchase intention. Organizations should focus on quality accompanying with incentives to whole sellers and retailers to push their products in market.

Training should provide to front line marketing employees for creating real image of product or services. Management should keep personality match of employee in marketing for effective impact on product offering.

\section{Limitations of the study}

Taken sample size of 300 is a very limited sample to generalize the results of the study; results may differ from using any other sample. Apart from this it is a confined study to one country so change in population selection results may vary. It is also a fact that respondents may rate celebrities according to their own liking and disliking of celebrity. Contrast study for Indian and Pakistan celebrities' data was collected at same time due to time limitation here longitudinal study may be effective. Well established endorsed brands are selected for the study where new brands may have different results even when endorsed by same celebrities.

\section{Conclusion}

Results of study are somehow contradict with the extant literature but are realistic in Pakistani context because people are brand loyal, their taste and choice preference is not due to celebrity attributes but due to their previous experience with product or service. So organizations should keep their product quality wise strengthen which ultimately will create their preferences. No doubt celebrity endorsement has effects on marketing effort but it is not necessary to hire expensive celebrities to accomplish the purpose in Pakistan. Newly developed products can be introduced by attractive, less expensive and expert models to create product awareness in market. In order to get market share cost effective and truly need based product should introduced for customers if firms deem to stay in market over long run.

\section{References}

Amos, C., Holmes, G., \& Strutton, D. (2008). Exploring the relationship between celebrity endorser effects and advertising effectiveness. International Journal of Advertising, 27(2), 209-234.

Brajesh, K., \& Gouranga, P. (2011). Celebrity Endorsement in FMCGs Advertising: A Case Study in a Culturally Vibrant Society. Advances in Management, 4 (8), 24-28

Belch, G., \& Belch, M. (1994). Introduction to advertising and promotion: An integrated Marketing communications perspective. Irwin: Homewood, 189-192

Choi, S. M., Lee, W. \& Kim, H. (2005). Lessons from the rich and famous: A cross-cultural comparison of celebrity endorsement in advertising. Journal of Advertising, 34 (2), 85-98

Desphande, R., \& Stayman, D. M. (1994). A tale of two cities: Distinctiveness theory and advertising effectiveness. Journal of Marketing Research, 5764.

Erdogan, B. Z. (1999). Celebrity endorsement: a literature review. Journal of Marketing Management, 15(4), 291-314.

Erdogan, B. Z., Baker, M. J., \& Tagg, S. (2001). Selecting celebrity endorsers: the practitioner's perspective. Journal of Advertising Research, 41(3), 3949

Jagre, E., Watson, J. J., \& Watson, J. G. (2001). Sponsorship and congruity theory: A theoretical framework for explaining consumer attitude and recall of event sponsorship. Advances in Consumer Research, 28, 439445 .

Fortini-Campbell, L. (1992, January). Hitting the sweet spot. Copy Workshop.

Friedman, H and Friedman. L. (1979), Endorser Effectiveness by Product type, Journal of Advertising Research, 19(5), 63-71

Goldsmith, R. E., Lafferty, B. A., \& Newell, S. J. (2000). The impact of corporate credibility and celebrity credibility on consumer reaction to advertisements and brands. Journal of Advertising, 43-54.

Gan, W. (2006). Effectiveness of Celebrity Endorsement Advertising in Chinese Marketplace (Doctoral dissertation, University of Nottingham). Chinese Marketplace. http://edissertations.nottingham.ac.uk/225/1/06MAlixwg1.pdf>

Hung, K., Chan, K. W., \& Tse, C. H. (2011). Assessing celebrity endorsement effects in China: a consumer-celebrity relational approach. Journal of Advertising Research, 51(4), 608-623

Hovland Carl I., Janis, L. Irving, and Kelley, Harold H. (1953). Communication and Persuasion, New Haven, CT: Yale University Press.

Kahle, L.R.and Homer, P.M. (1985). Physical attractiveness of the celebrity endorser: A social adaptation perspective. Journal of Consumer Research, 11(4), 954-961.

Kamins, M.A. (1990), An Investigation into the 'Match-Up' Hypothesis in Celebrity Adverting: When Beauty Is Only Skin Deep, Journal of Advertising, 19 (1), 4-13.

Kamins, M. A., \& Gupta, K. (1994). Congruence between spokesperson and product type: A matchup hypothesis perspective. Psychology \& Marketing, 11(6), 569-586.

Kotler, P (1997), Marketing Management Analysis. Planning, Implementation, and Control, 9th Edition, Englewood Cliffs, NJ: Prentice-Hall

Lafferty, B. A., \& Goldsmith, R. E. (1999). Corporate credibility's role in consumers' attitudes and purchase intentions when a high versus a low credibility endorser is used in the ad. Journal of business research, 44(2), 109-116.

McCracken, G. (1989). Who is the celebrity endorser? Cultural foundations of the endorsement process, Journal of consumer research, 16(12), 310-321 
Menon, K., Boone, L. E., \& Rogers, H. P. (2001). Celebrity Advertising: An assessment of its relative effectiveness. Retrieved June, 20, 2009. http://sbaer.uca.edu/research/sma/2001/04.pdf

McCuthceon, L. E., Lange, R., \& Houran, J. (2002). Conceptualization and measurement of celebrity worship. British Journal of Psychology, 93(1), 67-87.

Misra, S., \& Beatty, S. E. (1990). Celebrity spokesperson and brand congruence: An assessment of recall and affect. Journal of Business Research, 21(2), 159-173.

Ohanian, R. (1990). Construction and validation of a scale to measure celebrity endorsers. perceived expertise, trustworthiness, and attractiveness. Journal of Advertising, 19, 39-52.

Ohanian, R. (1991). The impact of celebrity spokespersons' perceived image on consumers' intention to purchase. Journal of Advertising Research, 31(1), 46-54.

\section{Appendix}

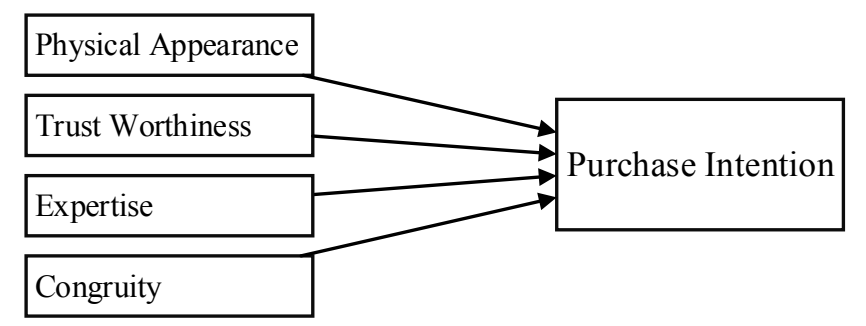

Conceptual Frame Work:

Source: Author self-developed

\section{Data Collection Instruments}

\section{Case of Pakistan Celebrities}
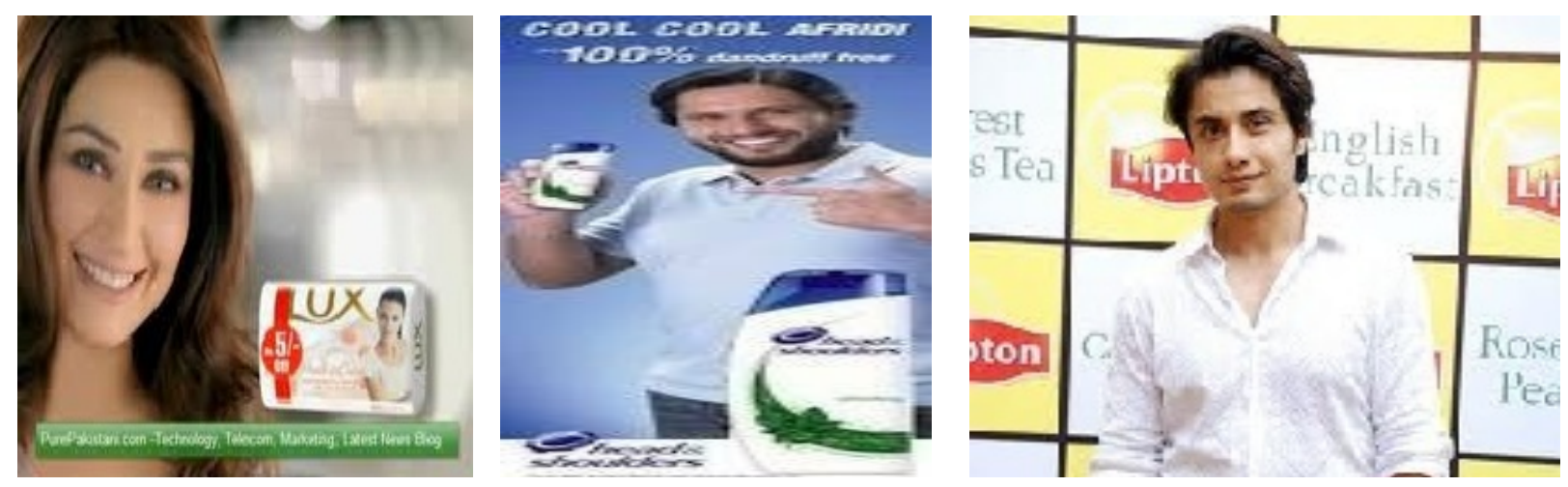

Strongly Agree (S.A) Agree (A) Neutral (N) Disagree (D.A) Strongly Disagree (S.D)

Pornpitakpan, C. (2004). The effect of celebrity endorsers' perceived credibility on product purchase intention: The case of Singaporeans. Journal of International Consumer Marketing, 16(2), 5574.

Pringle, H., \& Binet, L. (2005). How marketers can use celebrities to sell more effectively. Journal of Consumer Behaviour, 4(3), 201-214.

Roy, S. (2006). An exploratory study in Celebrity Endorsements. Journal of creative communications, 1(2), 139-153.

Tripp, C., Jensen, T. D., \& Carlson, L. (1994). The effects of multiple product endorsements by celebrities on consumers' attitudes and intentions. Journal of Consumer Research, 20, 535-547.

White, D. W., Goddard, L., \& Wilbur, N. (2009). The effects of negative information transference in the celebrity endorsement relationship. International Journal of Retail \& Distribution Management, 37(4), 322-335.

\section{Section A:}

On a scale of 1 to 5 , please circle the number that best reflects your feelings towards the celebrity.

Celebrity physical attractiveness:

\begin{tabular}{|c|c|c|c|c|c|c|c|}
\hline & & S.A & $\mathbf{A}$ & $\mathbf{N}$ & D.A & S.D & \\
\hline 1 & Attractive & 1 & 2 & 3 & 4 & 5 & Unattractive \\
\hline 2 & Classy & 1 & 2 & 3 & 4 & 5 & Not classy \\
\hline 3 & Beautiful & 1 & 2 & 3 & 4 & 5 & Ugly \\
\hline 4 & Elegant & 1 & 2 & 3 & 4 & 5 & Plain \\
\hline 5 & Sexy & 1 & 2 & 3 & 4 & 5 & Not Sexy \\
\hline
\end{tabular}

Celebrity crediblity:

\begin{tabular}{|c|c|c|c|c|c|c|c|}
\hline & & S.A & $\mathbf{A}$ & $\mathbf{N}$ & D.A & S.D & \\
\hline 6 & Dependable & 1 & 2 & 3 & 4 & 5 & Not dependable \\
\hline 7 & Honest & 1 & 2 & 3 & 4 & 5 & Dishonest \\
\hline 8 & Reliable & 1 & 2 & 3 & 4 & 5 & Unreliable \\
\hline 9 & Sincere & 1 & 2 & 3 & 4 & 5 & Insincere \\
\hline 10 & Trustworthy & 1 & 2 & 3 & 4 & 5 & Not Trustworthy \\
\hline
\end{tabular}


Celebrity expertise:

\begin{tabular}{|c|c|c|c|c|c|c|c|}
\hline & & S.A & $\mathbf{A}$ & $\mathbf{N}$ & D.A & S.D & \\
\hline 11 & Expert & 1 & 2 & 3 & 4 & 5 & Not expert \\
\hline 12 & Experienced & 1 & 2 & 3 & 4 & 5 & Not experienced \\
\hline 13 & Knowledgeable & 1 & 2 & 3 & 4 & 5 & Unknowledgeable \\
\hline 14 & Qualified & 1 & 2 & 3 & 4 & 5 & UN Qualified \\
\hline 15 & Skilled & 1 & 2 & 3 & 4 & 5 & Unskilled \\
\hline
\end{tabular}

\section{Section B:}

On a scale of 1 to 5 , please circle the number that best reflects your feelings towards the following questions pertaining to the Congruency between the celebrity and the brand.

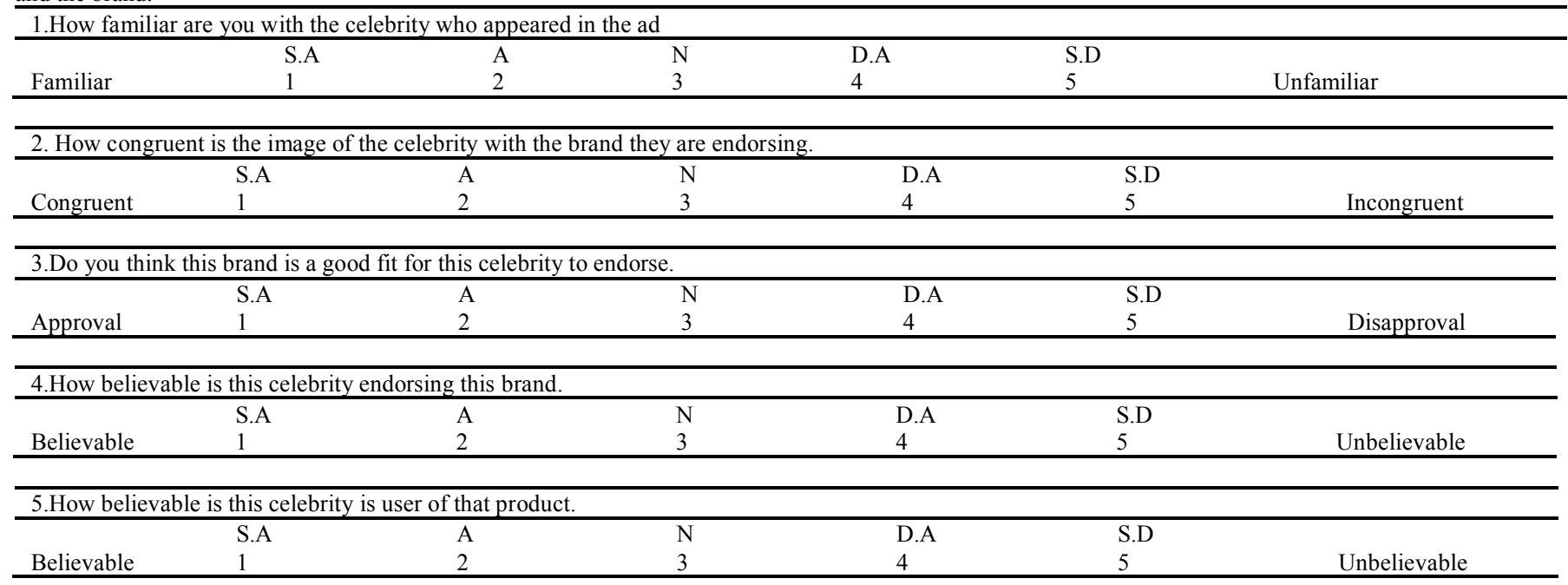

\section{Section C:}

On a scale of 1 to 5 , with 1 being "very unlikely" and 5 being "very likely", circle the number that best reflects your feelings towards the following questions pertaining to your intention to buy this product.

\begin{tabular}{|c|c|c|c|c|c|c|c|}
\hline Very likely & Likely & Somewhat Likely & \multicolumn{2}{|l|}{ Unlikely } & \multicolumn{2}{|c|}{ Very Unlikely } & \\
\hline 1 & 2 & 3 & 4 & & \multicolumn{2}{|c|}{5} & \\
\hline \multicolumn{3}{|c|}{ A) How likely you purchase this product } & 1 & 2 & 3 & 3 & 5 \\
\hline \multicolumn{3}{|c|}{ B) How likely are you to try this product on if seen in a store } & 1 & 2 & 3 & 3 & 5 \\
\hline \multicolumn{3}{|c|}{ C) How likely and actively you seek out the product in the store } & 1 & 2 & 3 & 3 & 5 \\
\hline \multicolumn{3}{|c|}{ D)Does presence of celebrity in ad encourage to buy the product } & 1 & 2 & 3 & 3 & 5 \\
\hline
\end{tabular}

\section{Section D:}

Please circle the appropriate Number for each of the following items

\begin{tabular}{llll}
\hline $\mathrm{A}$ & Gender & Male & Female \\
\hline $\mathrm{B}$ & My Age is & Years & \\
\hline
\end{tabular}

\section{Case of Indian Celebrities}
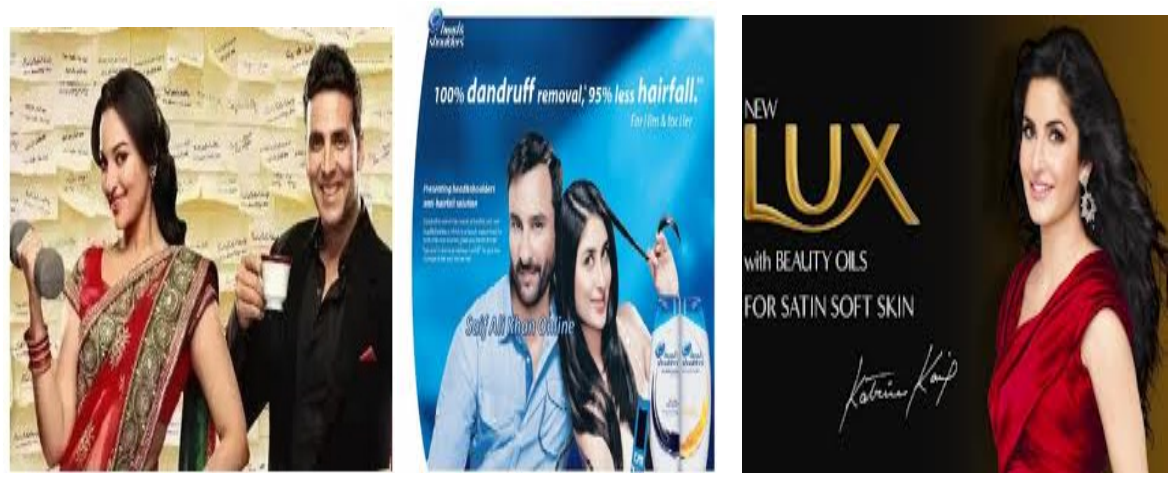


\section{Appendix}

Strongly Agree (S.A) Agree (A) Neutral (N) Disagree (D.A) Strongly Disagree (S.D)

Section A:

On a scale of 1 to 5 , please circle the number that best reflects your feelings towards the celebrity.

Celebrity physical attractiveness

\begin{tabular}{|c|c|c|c|c|c|c|c|}
\hline & & S.A & $\mathbf{A}$ & $\mathbf{N}$ & D.A & S.D & \\
\hline 1 & Attractive & 1 & 2 & 3 & 4 & 5 & Unattractive \\
\hline 2 & Classy & 1 & 2 & 3 & 4 & 5 & Not classy \\
\hline 3 & Beautiful & 1 & 2 & 3 & 4 & 5 & Ugly \\
\hline 4 & Elegant & 1 & 2 & 3 & 4 & 5 & Plain \\
\hline 5 & Sexy & 1 & 2 & 3 & 4 & 5 & Not Sexy \\
\hline
\end{tabular}

Celebrity crediblity

\begin{tabular}{lllllll}
\hline & S.A & A & N & D.A & S.D \\
\hline 6 & Dependable & 1 & 2 & 3 & 4 & 5 \\
7 & Honest & 1 & 2 & 3 & 4 & 5 \\
8 & Reliable & 1 & 2 & 3 & 4 & 5 \\
9 & Sincere & 1 & 2 & 3 & 4 & 5 \\
10 & Trustworthy & 1 & 2 & 3 & Not dependable & Dishonest \\
\hline
\end{tabular}

Celebrity expertise

\begin{tabular}{|c|c|c|c|c|c|c|c|}
\hline & & S.A & $\mathbf{A}$ & $\mathbf{N}$ & D.A & S.D & \\
\hline 11 & Expert & 1 & 2 & 3 & 4 & 5 & Not expert \\
\hline 12 & Experienced & 1 & 2 & 3 & 4 & 5 & Not experienced \\
\hline 13 & Knowledgeable & 1 & 2 & 3 & 4 & 5 & Unknowledgeable \\
\hline 14 & Qualified & 1 & 2 & 3 & 4 & 5 & UN Qualified \\
\hline 15 & Skilled & 1 & 2 & 3 & 4 & 5 & Unskilled \\
\hline
\end{tabular}

\section{Section B:}

On a scale of 1 to 5 , please circle the number that best reflects your feelings towards the following questions pertaining to the Congruency between the celebrity and the brand.

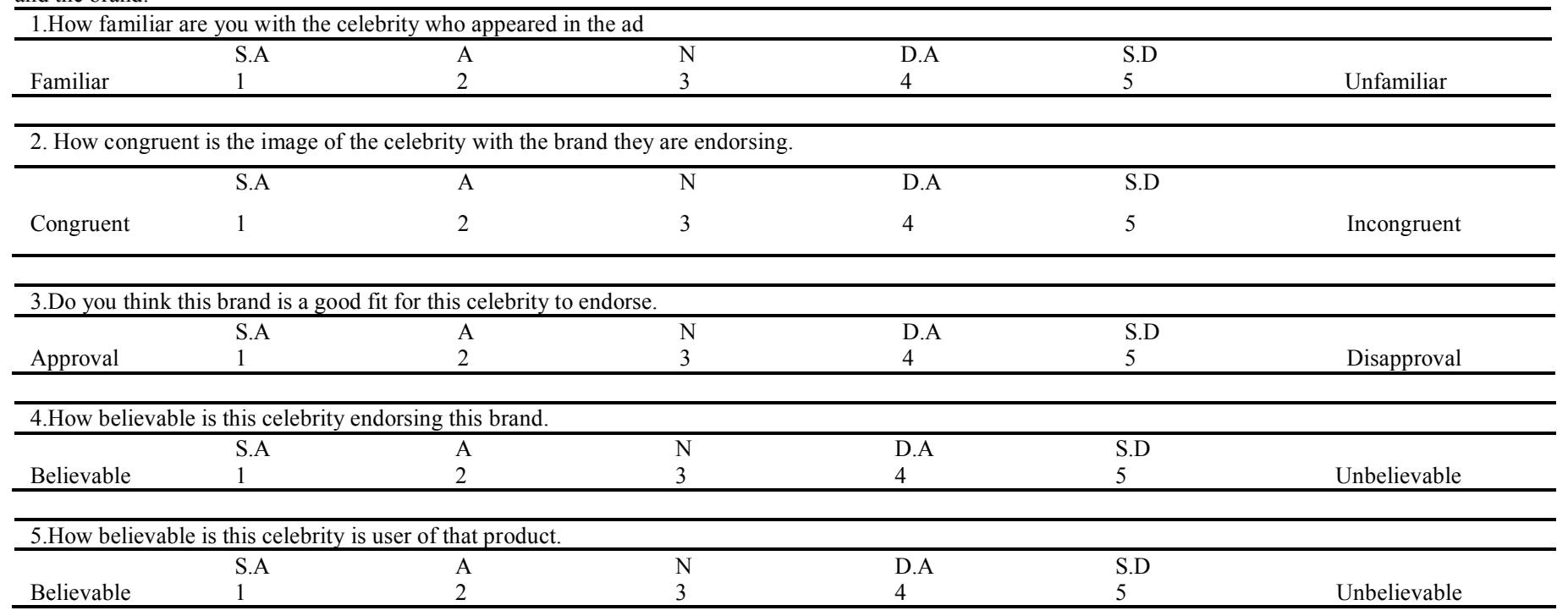

\section{Section C:}

On a scale of 1 to 5 , with 1 being "very unlikely" and 5 being "very likely", circle the number that best reflects your feelings towards the following questions pertaining to your intention to buy this product

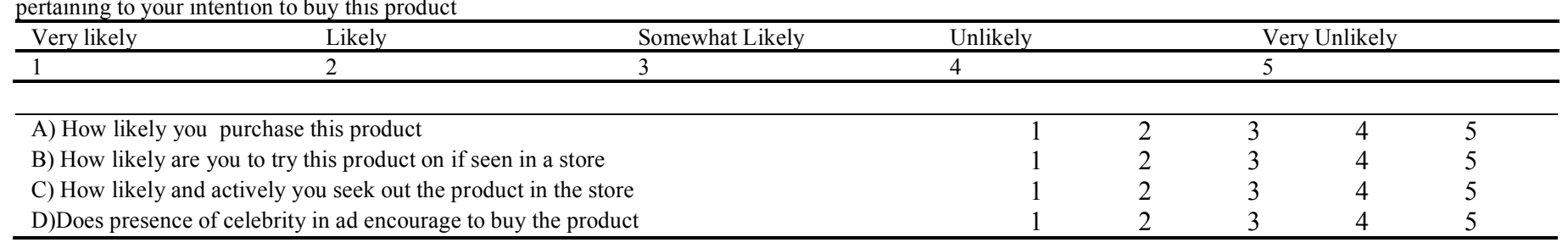

\section{Section D:}

Please circle the appropriate Number for each of the following items.

\begin{tabular}{lll}
\hline $\mathrm{A}$ & Gender & Male \\
\hline $\mathrm{B}$ & My Age is & Years \\
\hline
\end{tabular}

